cancer and gives an excellent review of the subject from Whipple (1 935) to Cattell (1949).

The book is strongly commended, its only drawback being its price.

S.T.

\section{ADVANCES IN INTERNAL MEDICINE. VOL. III}

Edited by William Dock, M.D., and I. SNapper, M.D. Pp. xiii +478 . London and New York: Interscience Publishers. 1949. 68s.

It is the beauty of books such as this that they provide a reasonably understandable scientific basis for some of the clinical procedures and modern therapeutics that might otherwise be regarded purely as the outcome of empiricisms.

The section on BAL reviews the fascinating experimental work which established it as one of the mainstays in the treatment of metallic poisoning. The clinician will here receive the answer why he must maintain a very high blood concentration in the early stages of poisoning, as otherwise indeed the toxic effects might be enhanced.

Haemolytic anaemia is dealt with competently by Estren and Damashek. These two names assure a high standard, and one would have difficulty in finding a more concise and up to date summary.

Penicillin, streptomycin, histoplasmosis, antithyroid compounds, enzymic methods in diagnosis, plasma fractionation, acclimatization to heat and therapeutic agents in neurological disorders are the other subjects dealt with in this volume.

The standard throughout is high, the references extensive, and the paper and printing good. One might have wished for more detailed discussion of the therapeutic aspects of cerebro-vascular catastrophies, but perhaps that would go beyond the scope of the book. Altogether, not an easy book to read, but one which will fully repay the effort of the physician who has not lost the desire to enquire into the why and wherefore of medicine and therapy.

F.W.W.

\section{ENGLISH INDEX TO SOVIET MEDICAL PERIODICALS AVAILABLE IN LONDON LIBRARIES. VOL. I, I945-47}

By Donovan 'T. Richnell, B.A., F.L.A. Pp. xi 93. London: H. K. Lewis. 1950. £I.

The purpose of the above publication is to make more widely known current contributions of the Soviet Union to medical science, which aim it achieves very fully.

As the title says, it provides a guide to those journals which can readily be consulted in the main libraries in London. For this reason it is not a complete survey of all Soviet medical publications. Nevertheless, such a work, giving the title in Eng- lish, is of obvious importance to any research worker interested.

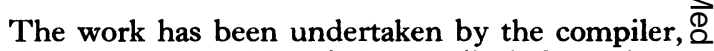
under the sponsorship of the Medical Committee. . of the Society for Cultural Relations, with the $\vec{F}$ knowledge that a good deal of work in Soviet medical of journals, though the journals are available, has been을 inaccessible because they have not been indexed in $\bar{E}$ any of the recognized reference works and very $\frac{\bar{\rho}}{\bar{b}}$ few are abstracted in the abstracting journals.

\section{PRINCIPLES OF OPHTHALMOLOGY}

By Thomson Henderson, M.D. Pp. 230, with $82 \overrightarrow{\vec{\omega}}$ illustrations. London: William Heinemann. 1950. 20 .

This small well-illustrated work is based upon. studies of the comparative anatomy of ocular $N$ structure in man and some 200 mammals of diverse $\omega$ orders, and the accounts given provide a welcome $\omega$ addition to the ophthalmologist's library. The clinical problems of accommodation and pressure 0 anomalies are presented in fresh perspective against $\stackrel{ }{\supset}$ this background and, although the somewhat novel $\vec{c}$ arguments with which the author supports his views of the pathogenesis of ocular hypertension are not? likely to receive general assent, the student will find here a considerable amount of new material.

\section{MEDICAL ANNUAL, $195^{\circ}$}

\section{Bristol: John Wright and Sons Ltd.}

The standard expected of this annual has beenฏ maintained in the present edition. It is always a⿳亠े pleasure when new editions of the "Medical Annual' are published, and the reviewers haveō achieved balanced and impartial essays on their 3 subjects. There are several interesting and im-? portant contributions in the present issue, includ-o ing, amongst others, a review and extensive biblio-응 graphy on geriatrics by Dr. Marjorie Warren, an article on certain aspects of social medicine and, $\dot{0}$ what is a new feature in the annual, a section on aviation medicine. There is also an interesting re-i̊ view of work in connection with the thyroid gland, including the use of radio-active iodine and the thiouracil group of drugs. The indications for? operation in cases of congenital cardiovascular $\frac{D}{O}$ disease are also considered.

The book is, as usual, well illustrated and will be N of wide interest to all specialists as well as to general practitioners. The publishers are to be con- $\mathcal{O}$ gratulated on another well produced edition with many helpful diagrams and illustrations. Everyo member of the profession would benefit by readinge through this short and significant summary of the year's best contribution to medicine and surgery. \&

Not the least value in the book is the practitioner's index of recent pharmaceutical preparations andmedical and surgical appliances.

P.M. 